\title{
ACESSO CONTROLADO AO MORRO SÃO CAETANO EM PORTO ALEGRE: estudo de caso
}

CONTROLLED ACCESS TO THE MORRO SÃO CAETANO IN PORTO ALEGRE: a case study

\author{
Voltaire de Freitas Michel ${ }^{1}$ \\ Marc Antoni Deitos ${ }^{2}$
}

Resumo: O artigo é resultado de pesquisa que envolveu o estudo de um caso da cidade de Porto Alegre, mais especialmente no Morro São Caetano, em que a comunidade se dividiu entre os que buscavam a possibilidade de restringir o acesso ao loteamento, mediante colocação de cancelas e outros instrumentos, e aqueles que se opunham à tal implementação. O caso envolveu a análise da intervenção do Ministério Público, do Município de Porto Alegre e, finalmente, do Poder Judiciário, sob cuja responsabilidade se encontra, atualmente, a decisão a respeito da constitucionalidade da lei municipal que permitiu a implantação do acesso controlado. O estudo analisa as dificuldades apresentadas pela sobreposição da legislação nacional e municipal, assim como os aspectos constitucionais envolvidos. Os métodos empregados são exploratórios, com o exame de processos judiciais e extrajudiciais nos sites do Ministério Público e do Poder Judiciário; da legislação nacional e municipal, assim como da doutrina já produzida a respeito do assunto. Os resultados da pesquisa e as considerações finais correm no sentido de que os vícios da legislação municipal não são superados pela nova lei federal, porém a lei federal dá espaço à regulamentação desses empreendimentos, desde que interpretada em conformidade com as restrições constitucionais.

Palavras-chave: Direito Constitucional; Direito Imobiliário; Lei de Loteamentos; Loteamentos fechados; acesso controlado.

\footnotetext{
${ }^{1}$ Doutor em Direito pela Universidade Federal do Rio Grande do Sul (UFRGS) Mestre em Direito pela Universidade Federal do Rio Grande do Sul (UFRGS) Bacharel em Direito pela Universidade Federal do Rio Grande do Sul (UFRGS) Professor doCurso de Direito da IMED Porto Alegre. Brasil E-mail: voltairemichel@hotmail.com

2 Doutor em Direito pela UFRGS

Mestre em Relações Internacionais pela UFRGS

Diretor do Campus Porto Alegre da IMED

Professor no Curso de Direito da IMED. Brasil. E-mail: antonideitos@hotmail.com
} 
Abstract: The article is a result of research that involved the study of a case of the city of Porto Alegre, more especially in the Morro São Caetano, in which the community was divided among those who sought the possibility of restricting access to the subdivision by placing gates and other instruments, and those who opposed the implementation of such equipment. The case studied involved the analysis of the intervention of the Public Prosecution Office, the Municipality of Porto Alegre and, finally, the Judiciary, under whose responsibility is currently the decision regarding the constitutionality of the municipal law that allowed the implementation controlled access in subdivisions pre-existing ones. The study includes an analysis of the difficulties presented by the overlapping of national and municipal legislation, as well as the constitutional aspects involved. The methods used are exploratory, with the examination of judicial and extrajudicial proceedings in the websites of the Public Prosecution and Judicial Branch; examination of national and municipal legislation as well as of the doctrine already produced on the subject. The results of the research and the final considerations are that the vices of municipal legislation are not superseded by the new federal law, but the federal law gives room for the regulation of these enterprises, provided they are interpreted in accordance with constitutional restrictions.

Keywords: Constitutional Law; Property Law; Allotments, Gated communities; controlled access.

\section{INTRODUÇÃO}

A disseminação de empreendimentos imobiliários com acesso controlado, associada ao recrudescimento da violência nas grandes cidades brasileiras, é a razão por detrás das iniciativas de implantação de restrição de acesso a bairros e empreendimentos pré-existentes. Independente das críticas dos urbanistas e arquitetos, que atribuem a esses empreendimentos uma descaracterização do ambiente urbano, o certo é que há uma pressão social em seu favor, sobretudo em bairros de classe média cercados por populações marginalizadas.

O presente trabalho é um estudo de caso elaborado a partir do exame da situação atual do Morro São Caetano, em Porto Alegre, localizado no bairro Teresópolis. Um típico bairro de classe média, exclusivamente residencial, é palco atualmente de um acentuado conflito entre moradores que defendem a instalação de cancelas para a restrição de acesso e, por outro lado, proprietários que se opõem ao movimento, pelas mais variadas razões ${ }^{3}$. Parte dos moradores encontra-se

\footnotetext{
3 "Moradores e lideranças comunitárias do Morro São Caetano foram recebidos pelo vice-prefeito Sebastião Melo em seu gabinete para tratar da utilização de áreas públicas localizadas na comunidade. A utilização de cinco praças para projetos sociais foi solicitada pelos dirigentes da Associação dos Moradores e Proprietários
} 
representada pelas associações: Associação Morro São Caetano (AMOSC) e Associação dos Proprietários de Imóveis no Morro São Caetano (APROMOSC). O exame dos inquéritos civis e notícias de fato, que tramitam no Ministério Público do Rio Grande do Sul, dão conta de que há moradores, integrantes ou não das aludidas associações, que se opõem ao projeto de colocação de cancelas e vigilância nas vias de acesso ao Morro São Caetano. Nesse caso concreto, as tentativas de solução consensual não foram exitosas, não obstante as vantagens dessa forma de composição dos litígios (MELLO, 2017). O estudo desse caso justifica-se, em primeiro lugar, por sua complexidade, pois envolve o exame da legislação municipal recente, a legislação federal que introduziu a figura do loteamento controlado, e a própria constitucionalidade de ambas leis; em segundo lugar, o caso interessa porque relata uma experiência que se inicia na fase extrajudicial, com as tratativas levadas a efeito pelo Ministério Público para a composição entre as partes, passa pelo exame da ação já proposta pelo Ministério Público a respeito do tema e, prospectivamente, é de se reconhecer que certamente a questão somente encontrará uma resposta definitiva nos tribunais superiores. O estudo de caso se justifica visto que serve ao propósito de trazer ao plano nacional uma questão local, que alia uma série de variáveis que poderão estar presentes em situações análogas

O artigo estrutura-se em duas partes: na primeira parte, examina-se a trajetória legislativa da regulamentação do acesso controlado no Brasil e em Porto Alegre; na segunda parte, procede-se ao exame da trajetória extrajudicial e judicial do caso concreto do Morro São Caetano, em Porto Alegre.

A metodologia empregada é exploratória, com o exame da legislação nacional e municipal, assim como o exame dos autos de expedientes extrajudiciais e judiciais, disponíveis online. A bibliografia a respeito do tema, acesso controlado em empreendimentos pré-existentes, é limitada,

do Morro São Caetano (Apromosc), que estava representada por Dorolina Matos, Alexandre Lunardi, Ana Girotto, Alexandre Lunardi, Pedro Paulo Andrade e Darvil Bozzetto. 'Nós queremos uma cancha de bocha para uso dos idosos e espaço para recreação das crianças e adolescentes', salientou Darvil Bozzeto. A reunião foi acompanhada pelo secretário da Secretaria Municipal do Meio Ambiente, Cláudio Dilda, designado pelo viceprefeito Sebastião Melo para dar andamento ao processo de elaboração do decreto do Termo de Permissão de Uso, junto ao departamento jurídico da pasta. A representação dos moradores mostrou uma série de mapas com a localização das áreas. O gestor de excelência em serviços do Centro Administrativo Regional (CAR) Centro Sul, Fabiano Silva de Souza, vai visitar as praças e auxiliar a comunidade no encaminhamento das demandas junto aos órgãos da prefeitura. Posteriormente, o processo será avaliado pelo gabinete do prefeito José Fortunati. O acesso ao Morro São Caetano é pela rua Fernando Osorio, no bairro Teresópolis". PEREIRA, Ocimar. Moradores pedem permissão de uso de áreas no Morro São Caetano. Prefeitura de Porto Alegre. Relações Institucionais e Articulação Política, 08 abr. 2015. Disponível em: <http://www2.portoalegre.rs. gov.br/smgl/default.php?p_noticia=176874\&MORADORES+PEDEM+PERMISSAO+DE+USO+DE+AREAS+NO+M ORRO+SAO+CAETANO>. Acesso em: 22 ago. 2018.

${ }^{4}$ Como pode ser visto em: GERMANO, Paulo. Moradores instalam cancela em rua da zona sul de Porto alegre e geram polêmica. Gaúcha ZH, 14 jun. 2018. Disponível em: <https://gauchazh. clicrbs.com.br/colunistas/paulo-germano/noticia/2018/06/moradores-instalam-cancela-em-rua-da-zona-sulde-porto-alegre-e-geram-polemica-cjieg15ug0g7z01qoumrft1fw.html>. Acesso em: 22 ago. 2018. 
porém encontra-se indicada nas referências bibliográficas. As conclusões esboçam uma perspectiva da solução a ser atribuída à questão, a partir do julgamento da ação civil pública já ajuizada e seus prováveis desdobramentos.

\section{TRAJETÓRIA LEGISLATIVA DA REGULAMENTAÇÃO DO ACESSO CONTROLADO NO BRASIL E EM PORTO ALEGRE}

Nessa primeira parte, encaminha-se uma análise da situação dos loteamentos de acesso controlado no Brasil antes e depois da Lei no 13.465/2017, assim como as questões suscitadas pela Lei Municipal de Porto Alegre № 12.192/2016.

\subsection{PLANO NACIONAL: SITUAÇÃO ANTERIOR À LEI № 13.465/2017}

A pretensão de regular o acesso a bairros ou loteamentos, motivada externamente pela necessidade de aumentar os níveis de segurança, impôs-se como um fato nas grandes cidades brasileiras, que pouco amparo recebia da legislação. Apesar da ausência de respaldo legal, o fato da existência de tais empreendimentos provocou a criatividade dos operadores, juristas ou empreendedores. No direito brasileiro, à míngua de uma norma nacional a respeito, verificava-se a adoção de pelo menos duas modalidades de regularização dos chamados loteamentos ou condomínios fechados: a figura do condomínio horizontal de lotes, baseada na Lei no 4.591/64; ou o loteamento comum, amparado na Lei no 6.766/79, seguido de uma concessão de uso das vias públicas aos proprietários dos lotes, mediante ato administrativo.

A figura do condomínio horizontal de lotes encontrava algum prestígio na doutrina (ERPEN, MEZZARI, PAIVA, 2003). Nessa modalidade, alegadamente compatível com a Lei das Incorporações Imobiliárias, a área do empreendimento é parcelada e a unidade autônoma é o lote, sem a construção de casas. Em princípio, esse tipo de empreendimento não se enquadraria no conceito de loteamento, pois não há entrega de sistema viário e equipamentos públicos para o poder público, aplicando-se o regime da Lei no 4.591/64 e do Código Civil (RIZZARDO, 2010). Como não se trata propriamente de loteamento, mas de condomínio horizontal de lotes, também não há a reserva de 35\% de áreas públicas, percentual que, a partir da mudança da Lei no 6.766/79, pode ser determinado pelos municípios. Segundo Erpen, Mezzari e Paiva (2003), esse tipo de empreendimento buscaria seu fundamento, em primeiro lugar, no art. 8o da Lei no 4.591/64, combinado com o art. 3 do Decreto-Lei no 271/1967, que expressamente determina a aplicação da Lei no 4.591/64 aos loteamentos e equipara as normas de infraestrutura do condomínio horizontal 
à construção. Conforme os defensores dessa modalidade, os percentuais próprios do condomínio horizontal seriam definidos pela dimensão dos lotes, independente das construções posteriores, que seriam tratadas como acessões (PAIVA 2016; ERPEN, MEZZARI, PAIVA, 2003).

Essa solução, embora aparentemente bem respaldada pela Lei no 4.591/64 e pelo DecretoLei no 271/1967, enfrentava algumas objeções. Em primeiro lugar, o art. 3ำ do Decreto-Lei, ao equiparar o loteamento urbano ao condomínio, colocou em segundo plano as exigências de natureza urbanística e ambiental, sobretudo a necessidade de entrega de áreas ao poder público e a necessidade de licenciamento ambiental, exigida dos loteamentos, porém não dos condomínios edilícios (ARAÚJO, 2004).

No mesmo sentido, a lição de José Afonso da Silva (2000):

\begin{abstract}
Esse dispositivo, na real verdade, tem sido usado abusivamente para fundamentar os tais loteamentos fechados. Foi ele estabelecido, certamente, não para tal finalidade, mas para possibilitar o aproveitamento de áreas de dimensão reduzida no interior das quadras, que, sem arruamento, permitam a construção de conjuntos de edificações, em forma de vilas, sob regime condominial. (...) Quando, no entanto, a situação extrapola desses limites, para atingir o parcelamento de gleba com verdadeiro arruamento e posterior divisão da quadra em lotes, com aproveitamento das vias de circulação preexistentes, então aquele dispositivo não pode mais constituir fundamento do aproveitamento espacial, em forma de condomínio, porque aí temos formas de parcelamento urbanístico do solo, que há de reger-se pelas leis federais sobre loteamento e pelas leis municipais sobre a matéria urbanística, aplicáveis a esse tipo de urbanificação (SILVA, 2000, pp. 337-338).
\end{abstract}

As objeções certamente não passaram despercebidas pelos que sustentam o cabimento do condomínio horizontal de lotes, que sugerem, em paralelo, que o empreendedor, de certa forma, compense a comunidade com áreas, no percentual determinado pela lei municipal, em outros lugares, diversos da localização do empreendimento (PAIVA, 2016). O curioso, nessa solução proposta, é que nem a Lei no 4.591/64, nem o Decreto-Lei no 271, preveem essa modalidade de compensação, de modo que qualquer exigência nesse sentido seria, pelo menos, ilegal.

A propósito, o Tribunal de Justiça do Rio Grande do Sul, em precedente de 2007, rejeitou a aplicação do decreto, confirmando sentença proferida na Vara dos Registros Públicos de Porto Alegre, em que se afastou o modelo do condomínio horizontal de lotes em razão de sua desconsideração com os aspectos urbanísticos e ambientais (Apelação Cível no 70020348199).

Esse cenário encontrou uma significativa alteração com a promulgação da Lei $n$ o 13.465/2017, que acrescentou a Seção IV ao Capítulo VII do Código Civil, introduzindo a figura do "Do Condomínio de Lotes": 
Seção IV

Do Condomínio de Lotes

Art. 1.358-A. Pode haver, em terrenos, partes designadas de lotes que são propriedade exclusiva e partes que são propriedade comum dos condôminos. $\S 1$ ㅇ. A fração ideal de cada condômino poderá ser proporcional à área do solo de cada unidade autônoma, ao respectivo potencial construtivo ou a outros critérios indicados no ato de instituição.

$\S 2$ 2․ Aplica-se, no que couber, ao condomínio de lotes o disposto sobre condomínio edilício neste Capítulo, respeitada a legislação urbanística.

§ 3o Para fins de incorporação imobiliária, a implantação de toda a infraestrutura ficará a cargo do empreendedor (BRASIL, 2017, documento online).

De certa forma, aquela prática que se impunha na vida real consolidou-se, agora, em disposições legislativas.

A outra solução, também comum, era a constituição de um loteamento ordinário, com base na Lei no 6.766/76, com a posterior doação ou concessão das áreas públicas, sobretudo as vias, para os moradores, que se responsabilizariam por sua manutenção (COSTA, 2011). Segundo Paiva (2009), o loteamento fechado, constituído dessa forma, contaria com a autorização da administração municipal para que os proprietários restringissem o uso do bem público pela comunidade (ruas, praças etc.) e promovessem o cercamento e fechamento do perímetro, com instalação de portarias, cancelas, vigias etc. Essa é a solução que encontrava maior objeção e resistência na doutrina. Segundo Alves (2008, p. 67)

Atente-se que, na realidade, o fechamento de tais áreas loteadas ocorre, via de regra, desde a concepção do projeto imobiliário, em que o loteador/incorporador obtém o consentimento implícito do poder público municipal, lançando o empreendimento com a embalagem de um condomínio, ainda que se trate, tão somente, de um loteamento.

No mesmo sentido, Freitas (1998, p. 09),

Os municípios não podem autorizar essa forma de 'loteamento condominial'. Lei municipal que preveja ou regule sua implantação contamina o ato de aprovação de flagrante ilegalidade, porque o Município não tem competência legislativa em matéria de condomínio. 
A respeito da desafetação prevista no art. 70 do Decreto-Lei no 271, o mesmo autor acentua que

[...] essa peculiar fruição de imóvel público só pode ser conferida para os bens dominicais, sendo incompativel para os bens de uso comum ou especial, enquanto destinados aos fins precípuos. Estes últimos reclamariam prévia desafetação para a concessão exclusiva do uso, porque a utilização das vias públicas (bens de uso comum), por exemplo, não é uma mera possibilidade, mas um poder legal exercitável erga omnes, não podendo a Administração impedir o trânsito de pessoas de maneira estável, a menos que desafete a via [...] E, como se sabe, a desafetação de uma rua, ainda que precedida de autorização legislativa, deve conter um elemento fundamental: ter perdido, de fato, sua utilização pública, seu sentido de via de circulação, ter se tornado desabitada. Não basta a lei para desafetá-la. É preciso atender ao interesse público, como qualquer ato administrativo, sem o qual haverá fundamento para contestar a transmudação operada pela lei ordinária que promove a desafetação (FREITAS, 1998, p. 13).

Segundo Araújo (2004), alguns municípios previram em suas legislações essa possibilidade, vale dizer, a concessão aos particulares das áreas públicas decorrentes de loteamentos instituídos na forma da Lei no 6.766/76. A título de exemplo, menciona a autora a Lei no 8.736, de 09.01.1996, do Município de Campinas (SP), que "dispõe sobre a permissão a título precário de uso das áreas públicas de lazer e das vias de circulação, para constituição de loteamento fechados no Município de Campinas e dá outras providências"; a Lei no 3.270, de 15.01.1999, do Município de Americana (SP), que "dispõe sobre o parcelamento e o aproveitamento do solo no território do Município e dá outras providências; a Lei no 2.668, de 18.12.2003, do Município de Paulínia (SP), que "dispõe sobre loteamentos urbanos, loteamentos fechados e condomínios fechados no Município de Paulínia e dá outras providências"; a Lei no 9.244, de 19.11.2003, do Município de Londrina (PR), que "dá nova redação ao artigo 56 da Lei no 7.483, de 20 de julho de 1998, que dispõe sobre o parcelamento do solo para fins urbanos no Município de Londrina".

No caso específico do Rio Grande do Sul, um aspecto dificultaria a tentativa de regularização desses loteamentos "que foram fechados" com base em lei esparsa municipal: segundo expressa determinação da Constituição Estadual, os planos diretores, instrumentos fundamentais, deverão contar com um processo legislativo diferenciado, com a participação efetiva da sociedade ( $\$$ 5. do art. 177 da Constituição do Rio Grande do Sul: Os Municípios assegurarão a participação das entidades comunitárias legalmente constituídas na definição do plano diretor e das diretrizes gerais de ocupação do território, bem como na elaboração e implementação dos planos, programas e projetos que lhe sejam concernentes). Aliás, esse dispositivo tem sido o fundamento jurídico para o reconhecimento da inconstitucionalidade de leis municipais em face da Constituição Estadual. A julgar pela posição do Tribunal de Justiça do Rio Grande do Sul a respeito da necessidade de consulta 
popular nesses projetos, estariam sujeitas a objeções de natureza constitucional as eventuais leis de efeitos concretos que autorizassem a doação ou concessão das áreas aos moradores.

Outro óbice arguido contra esse modelo é a necessidade de se constituir, voluntariamente, uma pessoa jurídica, provavelmente uma associação, com o propósito de arcar com os ônus de manutenção das obras físicas de isolamento do condomínio. A esse respeito, o Supremo Tribunal Federal está na iminência de avaliar se a obrigação de adesão a essas associações encontra óbice constitucional, sobretudo no dispositivo constitucional que trata da liberdade de associação. A questão em foco, no Tema no 492 do Supremo Tribunal Federal, originado do Recurso Extraordinário № 695.911, em regime de repercussão geral, sob a relatoria do Ministro Dias Toffoli, é se é possível a "cobrança, por parte de associação, de taxas de conservação de loteamento imobiliário urbano de proprietário não associado". Como destacado por Custódio (2017), esse ponto diz respeito à relação interna dentro de um loteamento ou condomínio fechado. As questões externas, tais como a acessibilidade aos bens públicos e a restrição ao direito de ir e vir, ainda não se encontram submetidas para decisão em regime de repercussão geral, até a data de conclusão dessa pesquisa (MUKAI, 2016, p. 87-91; LIMA, 2007, pp. 26-39). Esses dois modelos, o condomínio de lotes e o loteamento de acesso controlado, foram, como se verificará, introduzidos no direito brasileiro pela Lei no $13.465 / 2017$.

\subsection{PLANO NACIONAL: SITUAÇÃO POSTERIOR À LEI № 13.465/2017}

A Lei № 13.465/2017 introduziu modificações na antiga Lei № 6.766, criando a figura do loteamento controlado. Ao incluir o $7^{\circ} \underline{0}$ ao art. $2^{\circ}$ da Lei de Loteamentos, dispôs que

Constitui loteamento de acesso controlado a modalidade de loteamento, definida nos termos do $\S 1^{\circ}$ deste artigo, cujo controle de acesso será regulamentado por ato do poder público Municipal, sendo vedado o impedimento de acesso a pedestres ou a condutores de veículos, não residentes, devidamente identificados ou cadastrados (BRASIL, 2017, documento online).

Mais adiante, na mesma lei, introduziu o art. 36-A, a cujo teor

As atividades desenvolvidas pelas associações de proprietários de imóveis, titulares de direitos ou moradores em loteamentos ou empreendimentos assemelhados, desde que não tenham fins lucrativos, bem como pelas entidades civis organizadas em função da solidariedade de interesses coletivos desse público com o objetivo de administração, conservação, manutenção, disciplina de utilização e convivência, visando à 
valorização dos imóveis que compõem o empreendimento, tendo em vista a sua natureza jurídica, vinculam-se, por critérios de afinidade, similitude e conexão, à atividade de administração de imóveis (BRASIL, 2017, documento online).

E destaca, no parágrafo único: "a administração de imóveis na forma do caput deste artigo sujeita seus titulares à normatização e à disciplina constantes de seus atos constitutivos, cotizandose na forma desses atos para suportar a consecução dos seus objetivos" (BRASIL, 2017, documento online). O novo art. 36-A deve ser lido, naturalmente, em consórcio com a nova modalidade de loteamento de acesso controlado, uma vez que propicia a busca dos recursos para o sustento da estrutura de controle. A nova lei resultou da conversão da Medida Provisória no 759, de 22 de dezembro de 2016, que durante sua tramitação recebeu 732 propostas de emendas e que, finalmente, deu origem à Lei no 13.465. Alguns dias após a sua sanção, a lei foi objeto de uma ação direta de inconstitucionalidade proposta pela Procuradoria-Geral da República (ADI no 5771), atualmente sob a relatoria do Ministro Luiz Fux, com pedido de medida liminar, ainda não apreciada. A ação direta de inconstitucionalidade tem como objeto a lei na sua integralidade, não se restringindo aos novos institutos, sobretudo o loteamento fechado e o condomínio de lotes (CUSTÓDIO, 2017).

\subsection{PLANO MUNICIPAL: A LEI MUNICIPAL DE PORTO ALEGRE (ANTECEDENTES)}

Em 30 de dezembro de 2016, o Município de Porto Alegre sancionou a Lei no 12.192/2016, que criou o Programa Municipal de Segurança das Comunidades. A lei municipal continha o seguinte texto:

Art. 1‥ Fica criado, no Município de Porto Alegre, o Programa Municipal de Segurança das Comunidades, destinado a fomentar as inciativas de segurança por parte das comunidades.

Parágrafo único. Para os fins desta Lei, consideram-se comunidades os núcleos urbanos, como bairros, vilas, ruas, avenidas, loteamentos residenciais e assemelhados.

Art. 2‥ Para atingir os objetivos do Programa criado nesta Lei, as comunidades poderão, por meio de entidades representativas legalmente constituídas, firmar convênio com o Município de Porto Alegre, para atuar, de forma conjunta e regulamentada, no exercício de inciativas que visem à segurança local.

Art. 3‥ As empresas que prestarem o serviço de vigilância referido nesta Lei deverão ser autorizadas pelo Grupamento de Supervisão de Vigilância e 
Guardas - GSVG - da Brigada Militar do Rio Grande do Sul, bem como ficarão sob sua fiscalização.

Art. 4‥ Visando a garantir a sua segurança, as comunidades poderão dispor de serviços de vigilância por meio de pessoal devidamente registrado, de equipamentos eletrônicos, como câmeras ou outros recursos tecnológicos de segurança, e de elementos físicos.

Art. 5o. No caso de comunidades que possuam acessos exclusivos de entrada e saída, poderão ser instalados equipamentos e alocado pessoal para manter a vigilância acerca da segurança local, nos termos a serem definidos no convênio referido no art. 20 desta Lei.

Art. 60 . As despesas com serviços de vigilância e equipamentos correrão por conta das comunidades que aderirem ao Programa criado nesta Lei (RIO GRANDE DO SUL, 2016, documento online).

De certa forma, sob o fundamento de implantar estratégias comunitárias de segurança pública, a nova lei municipal introduziu dispositivos de nítido caráter urbanístico, sobretudo quando previu que "as comunidades poderão dispor de serviços de vigilância por meio de pessoal devidamente registrado, de equipamentos eletrônicos, como câmeras ou outros recursos tecnológicos de segurança, e de elementos físicos" (art. 4o da Lei no 12.192/2016), e que "no caso de comunidades que possuam acessos exclusivos de entrada e saída, poderão ser instalados equipamentos e alocado pessoal para manter a vigilância acerca da segurança local, nos termos a serem definidos no convênio" (art. 50 da Lei no 12.192/2016).

Na Câmara Municipal de Porto Alegre já tramitava outro projeto semelhante, O PLL 230/2016, de iniciativa do Vereador Cássio Trogildo, que tem como objetivo regulamentar os "loteamentos fechados". O projeto, ainda em fase inicial do processo legislativo, em síntese, autoriza o "fechamento, a critério da Administração Municipal, dos loteamentos e ruas sem saída, desde que estejam os mesmos registrados e situados em zona classificada como predominantemente residencial unifamiliar - ZR, com acesso controlado de veículos e pessoas não domiciliadas no local". A título de condições para o fechamento, determina que o "o pedido para fechamento deverá ser formulado por no mínimo 50\% (cinquenta por cento) mais um dos proprietários dos imóveis existentes na área, através de Requerimento". Dentre as peças indispensáveis para o requerimento, menciona o projeto a "Identificação através dos números do R.G. e CPF de cada um dos requerentes, bem como o número de inscrição imobiliária municipal do imóvel respectivo" e "Prova de constituição de entidade jurídica representativa dos proprietários da área que terá obrigatoriedade entre suas finalidades a de ser a responsável pelas despesas com a instalação e manutenção dos elementos de fechamento da respectiva área". Além disso, o que é uma novidade dentre os instrumentos de regularização desses empreendimentos, o projeto destaca que "O fechamento das divisas da área poderá ser feito durante os horários das 20h:00min às 6h:00min sem obstáculos de 
efeito permanente, podendo apenas conter portão, cancelas, correntes ou similares" e que "o fechamento de que trata este artigo não pode obstruir serviços públicos, como manutenção, conservação e limpeza das ruas, calçadas e sinalização de trânsito; coleta de lixo; manutenção da iluminação pública; conservação e poda de árvores". Por fim, "o acesso de pedestres ou condutores de veículos não residentes nas respectivas áreas fechadas é garantido mediante simples identificação ou cadastramento, não podendo, em nenhuma hipótese, ocorrer a restrição ao mesmo" (MICHEL, 2017, pp. 946-947).

\section{TRAJETÓRIA EXTRAJUDICIAL E JUDICIAL DO CASO ESTUDADO}

Nessa segunda parte do estudo, explora-se, em primeiro lugar, a trajetória extrajudicial do caso no âmbito do Ministério Público; a trajetória judicial, com o exame da ação civil pública proposta; e, ao final, as perspectivas de solução para o caso.

\subsection{FASE EXTRAJUDICIAL: O INQUÉRITO CIVIL DO MINISTÉRIO PÚBLICO}

Na esfera do Ministério Público do Rio Grande do Sul, as questões urbanísticas, no Município de Porto Alegre, estão sob a responsabilidade da Promotoria de Justiça de Habitação e Defesa da Ordem Urbanística, com atribuições especializadas.

No Ministério Público do Rio Grande do Sul, os inquéritos civis, exceto em caso de sigilo necessário às investigações, são acessíveis pela internet, no link da instituição, inclusive com a possibilidade de consultar peças e documentos produzidos pela instituição e juntados pelas partes 5 . No caso concreto, inicialmente aportou ao Ministério Público uma representação de um dos moradores, ligado a uma das associações (Apromosc e Amosc), em abril de 2018, solicitando informações sobre a posição da instituição a respeito do projeto das cancelas no Morro São Caetano, em razão do convênio celebrado com o Município de Porto Alegre, com respaldo na já mencionada lei municipal. Antes mesmo dessa manifestação, já haviam aportado ao Ministério Público várias notícias de fatos relacionados com o mesmo conflito. As representações e notícias nesse sentido não geraram a instauração de inquéritos civis porque a questão já se encontrava judicializada a partir da ação civil pública ajuizada pelo Ministério Público, no Inquérito Civil no 01629.000.208/2017, buscando ver reconhecida, incidentalmente, a inconstitucionalidade da lei municipal que autorizava os convênios. A decisão de indeferimento de instauração de inquérito civil constante da notícia de

\footnotetext{
5 Link para a tramitação da investigação relativa às cancelas no Morro São Caetano. Disponível e: <https://www.mprs.mp.br/atendimento/consulta-processo/processo/?sis=SIM\&id=250221>.
} 
fato $\mathrm{n}$ 0 01629.000.256/2018 registra a inviabilidade de uma conciliação entre os moradores contra e a favor da medida, sobretudo em razão da animosidade entre as partes (Evento no 21 da notícia de fato).

Ainda na fase extrajudicial, um relatório produzido pelo Ministério Público, em junho de 2018 (evento no 38 do Procedimento no 01629.000.223/2018), dá conta de que de fato foram instaladas as cancelas, que no momento da vistoria se encontravam erguidas, e de uma guarida, com guarda uniformizado. Foram instaladas ainda câmeras e avisos de que a região é videomonitorada. Segundo informações obtidas durante a vistoria, em junho de 2018, com os próprios guardas contratados, as cancelas não estavam sendo fechadas, e aguardavam uma posição final dos moradores a respeito.

\subsection{FASE JUDICIAL: A AÇÃO CIVIL PÚBLICA PROPOSTA PELO MINISTÉRIO PÚBLICO}

Diante da nova lei municipal de Porto Alegre, e da existência de outros casos semelhantes ao do Morro São Caetano em Porto Alegre, o Ministério Público do Rio Grande do Sul, pela Promotoria de Justiça de Habitação e Defesa da Ordem Urbanística, ajuizou ação civil pública, firmada pelo Dr. Cláudio Ari Mello, contra o Município de Porto Alegre, buscando a sua condenação à obrigação de não fazer, de não celebrar os aludidos convênios. Nessa ação civil pública, a causa de pedir é a inconstitucionalidade da lei municipal, que permite ao município firmar convênios com entidades representativas de núcleos urbanos para contratar empresas visando a prestação de serviço de segurança privada em áreas públicas e a instalação de estruturas de controle de acesso a bens públicos de uso comum do povo. Em breve síntese, a ação não busca o reconhecimento da inconstitucionalidade em abstrato da lei municipal, mas o reconhecimento da inconstitucionalidade como causa de pedir, com as consequências daí decorrentes.

A ação não se destinava propriamente ao caso do Morro São Caetano, uma vez que outras comunidades se manifestaram pela celebração dos convênios, até mesmo ingressando no feito como assistente litisconsorcial do Município, como é o caso da Associação dos Moradores do Bairro Chácara das Nascentes.

Dentre os dispositivos constitucionais violados, segundo o Ministério Público, está o art. 144 da Constituição Federal, que atribuiu aos órgãos de segurança pública a responsabilidade pela segurança em áreas públicas; no mesmo sentido, o art. 124 da Constituição do Estado do Rio Grande do Sul. Além disso, a ação reputou inconstitucional o dispositivo da lei que permite a restrição de acesso aos bens públicos, buscando regular matéria que já está tratada no Código Civil, o regime dos bens públicos, tema de competência legislativa exclusiva da União; sustenta também a ação que o 
Município não dispõe de competência concorrente para legislar em matéria de direito urbanístico, exceto para (a) promover, no que couber, adequado ordenamento territorial, mediante planeamento e controle do uso, do parcelamento e do solo urbano (art. 30, VIII); (b) estabelecer política de desenvolvimento urbano (art. 182, caput) e (c) elaborar plano diretor (art. 182, §1으). Por fim, sustenta a ação que a lei viola as funções sociais da cidade, extraídas da interpretação do art. 182 da Constituição Federal, combinado com o art. 2o e seu inciso I do Estatuto das Cidades (Lei no 10.257/2001). Em breve síntese, a ação do MP reputa o art. 5 da Lei Municipal no 12.192/2016:

(i) formalmente inconstitucional por vício de iniciativa legislativa, por ofender a competência legislativa privativa para legislar sobre direito civil, que o art. 22, I da Constituição Federal atribui à União; (ii) formalmente inconstitucional por vício de iniciativa legislativa, por ofender a competência legislativa concorrente para legislar sobre direito urbanístico, que a Constituição Federal defere exclusivamente a União, Estados e Distrito Federal, excluindo os Municípios; e (iii) materialmente inconstitucional por violar o artigo 182, caput, da Constituição Federal.

A ação, distribuída para a 2a Vara da Fazenda Pública da Comarca de Porto Alegre, sob o no 9027011-90.2017.8.21.0001, obteve medida liminar, deferida pelo Dr. José Antônio Coitinho, em 24/07/2017, para o efeito de determinar ao Município de Porto Alegre que não firme qualquer convênio com entidade representativa de núcleos urbanos formados por bairros, vilas, ruas avenidas, loteamentos e assemelhados, nos termos dos artigos 2으, 3ㅇ, 4으, e 5으 da Lei Municipal no 12.192/2016. Não houve recurso contra a medida liminar concedida, que se encontra, portanto, vigente em Porto Alegre.

O mesmo tema, a constitucionalidade da Lei Municipal no 12.192/2016, foi submetido à Assessoria da Procuradoria-Geral de |Justiça do Rio Grande do Sul, gerando expediente que, no momento, encontra-se suspenso, aguardando a sentença a ser proferida na ação civil pública em curso na 2a Vara da Fazenda Pública. De qualquer forma, com a concessão da medida liminar, os efeitos que se obteria com o deferimento de medida liminar em ação direta de inconstitucionalidade já se encontram presentes com a medida já concedida.

Recentemente, em junho de 2018, as associações de moradores do Morro São Caetano ${ }^{6}$ ajuizaram "ação declaratória com pedido de liminar de tutela de urgência", contra o Município de Porto Alegre, distribuída por dependência à ação civil pública original; buscam os autores seja permitida a manutenção dos equipamentos de segurança já instalados no local, até a decisão

\footnotetext{
${ }^{6}$ Associação Morro São Caetano (Amosc); Associação dos Proprietários de Imóveis no Morro São Caetano (Apromosc).
} 
definitiva na ação civil pública. A medida liminar foi deferida, conforme informação disponibilizada no site do Tribunal de Justiça do Rio Grande do Sul (Processo no 9036618-93.2018.8.21.0001, CNJ)

Atualmente, no momento de elaboração deste trabalho, a ação civil pública originária encontra-se em fase de intimação das partes para que se manifestem a respeito do interesse na instrução probatória; o Ministério Público, pela Promotoria já mencionada, já se manifestou pelo julgamento do feito no estado em que se encontra, por se tratar de questão de direito, sem controvérsia fática.

\subsection{CONTROLE DA CONSTITUCIONALIDADE E PERSPECTIVA EM TRIBUNAIS SUPERIORES}

A solução jurídica do caso do Morro São Caetano passa pelo exame de duas normas de planos diversos. Em primeiro lugar, a Lei Municipal no 12.192/2016, que criou o Programa Municipal de Segurança das Comunidades, e permite que "as comunidades [...], por meio de entidades representativas legalmente constituídas, (possam) firmar convênio com o Município de Porto Alegre, para atuar, de forma conjunta e regulamentada, no exercício de iniciativas que visem à segurança local" (art. 2으), implicando a possibilidade de contratar "serviços de vigilância por meio de pessoal devidamente registrado, de equipamentos eletrônicos, como câmeras ou outros recursos tecnológicos de segurança, e de elementos físicos" (4ํ) e, ainda, "no caso de comunidades que possuam acessos exclusivos de entrada e saída, (instalar) equipamentos [...] para manter a vigilância acerca da segurança local, nos termos a serem definidos no convênio referido no art. 2 ㅇ desta Lei" (art. 5ㅇ).

Como já destacado anteriormente, a incompatibilidade da mencionada lei municipal com os dispositivos da Constituição Federal e Estadual parecem evidentes, e certamente constituem a parte mais controvertida da legislação municipal. A par da questão da segurança pública realizada por entidades particulares, a lei municipal expressamente autoriza a instalação de equipamentos para monitorar e manter a vigilância no local, em comunidades que possuam acessos exclusivos de entrada e saída. Eis o ponto em que a legislação municipal converge com os objetivos do novo instituto do loteamento fechado, introduzido no $\S 8$ o do art. 2ㅇ da Lei no 6.766/76, a cujo teor:

$\S 8^{\circ}$ Constitui loteamento de acesso controlado a modalidade de loteamento, definida nos termos do $\S 1^{\circ}$ deste artigo, cujo controle de acesso será regulamentado por ato do poder público Municipal, sendo vedado o impedimento de acesso a pedestres ou a condutores de veículos, não residentes, devidamente identificados ou cadastrados (Incluído pela Lei oㅡ 13.465, de 2017) (BRASIL, 2017, documento online). 
Em princípio, não se levando em consideração o exame da constitucionalidade material desse dispositivo, o certo é que ele ainda depende de uma regulamentação no âmbito municipal. A alusão a "regulamentado por ato do poder público municipal" permite inferir a desnecessidade de uma lei municipal em sentido estrito, e a ressalva final (vedado o impedimento de acesso a pedestres ou a condutores de veículos, não residentes, devidamente identificados ou cadastrados), parece ter sido incluída para evitar a evidente colidência com o dispositivo constitucional que garante a liberdade de ir e vir. No entanto, permanecem pelo menos duas prováveis inconsistências desse dispositivo com a Constituição: em primeiro lugar, o fato de que permite a restrição de acesso a bens de uso comum do povo (as vias públicas), aparentemente redefinindo os limites de seu conceito, introduzindo a figura do bem municipal de uso comum do povo de acesso restringível; e, ainda, uma provável colidência com a preservação da intimidade, uma vez que o acesso a esse bem de uso comum do povo (agora potencialmente restringível) depende de cadastro ou identificação. Certamente, tais medidas não gerariam qualquer controvérsia em bens de uso especial, cujo acesso controlado é indisputável, até para a preservação do serviço público.

\section{CONCLUSÕES}

O surgimento da legislação federal a respeito do loteamento de acesso controlado não parece ter colocado um fim na discussão jurídica sobre a viabilidade dessa modalidade de restrição e de uso da propriedade. No caso estudado, a lei municipal que amparava os convênios com o Município de Porto Alegre para o efeito de permitir às associações de moradores a contratação de segurança privada e a implantação de equipamentos de segurança, parece ser mais vulnerável, sob o ponto de vista da constitucionalidade, que a legislação federal. De qualquer forma, a legislação federal, ao permitir a regulamentação do loteamento de acesso controlado atribui-lhes a responsabilidade de sopesar, no regulamento, os óbices constitucionais de natureza material às comunidades de acesso restrito.

No exame do caso concreto, que ainda se encontra sub judice, é de se prever que, pelas questões constitucionais que envolve, tanto no contraste com a Constituição Federal, como no exame da Constituição do Estado do Rio Grande do Sul, a decisão final a respeito da constitucionalidade da legislação municipal deverá recair sobre o órgão naturalmente dotado de competência para tanto, o Supremo Tribunal Federal. 
É de se ressaltar, no entanto, que a própria constitucionalidade da Lei no 13.465 se encontra também em Pauta, na ADI no 5771, relatada pelo Min. Luiz Fux, ainda sem a concessão de medida liminar.

Os objetivos da pesquisa foram alcançados, sobretudo o de contribuir para o debate a respeito de questões que se reproduzem nas metrópoles brasileiras, quais sejam, o contraste entre os espaços públicos e a demanda por controle de acesso e segurança.

Como conclusão, acredita-se que o debate extrajudicial e judicial a respeito da constitucionalidade dos dispositivos da lei municipal e da lei federal contribuirá para uma maior cautela dos poderes públicos na regulamentação de institutos sensíveis como o loteamento de acesso controlado, sobretudo numa época de crise econômica e acentuada violência urbana.

\section{REFERÊNCIAS BIBLIOGRÁFICAS}

ALVES, Sonia Marilda Péres. "Loteamentos fechados" nas grandes cidades: a produção da ilegalidade por atores revestidos de poder social, econômico e político. Revista de Direito Imobiliário, São Paulo, v.31, n.64, pp.81-102, jan./jun. 2008.

ARAÚJO, Suely Mara Vaz Guimarães de. Condomínios urbanísticos. Consultoria Legislativa. Câmara dos Deputados. Estudo, abr. 2004. Disponível em:

<https://www.researchgate.net/publication/259332763_Condominios_urbanisticos>. Acesso em: 27 ago. 2018.

BRASIL. Lei no 13.465, de 11 de julho de 2017. Disponível em: <http://www.planalto.gov.br/ccivil_03/_Ato2015-2018/2017/Lei/L13465.htm>. Acesso em: 22 ago. 2018.

CALDEIRA, Teresa P. do Rio. Cidade de muros: crime, segregação e cidadania em São Paulo. São Paulo: Editora 34/Edusp. 2000.

COSTA, Valestan Milhomem da. A juridicidade dos loteamentos fechados com a publicidade no Registro de Imóveis. Revista de Direito Imobiliário, São Paulo, v.31, n.64, pp.103-154, jan./jun. 2008. 
CUSTODIO, Vinícius Monte. Análise jurídica do loteamento de acesso controlado e do condomínio de lotes na Lei Federal no 13.465/2017. Revista de Direito da Cidade, [S.I.], v. 9, n. 4, p. 1930-1952, out. 2017. ISSN 2317-7721. Disponível em: <http://www.epublicacoes.uerj.br/index.php/rdc/article/view/30871/21985>. Acesso em: 23 ago. 2018.

DE BARCELLOS, Tanya M.; MAMMARELLA, Rosetta. O significado dos condomínios fechados no processo segregação espacial nas metrópoles. Anais: Encontros Nacionais da ANPUR, [S.I.], v. 12, maio 2013.

Padrões sociais de territorialidade e condomínios fechados na Metrópole Gaúcha. Disponível em: <http://www.fee.rs.gov.br/wp-content/uploads/2014/03/20140324046.pdf>. Acesso em: 27 ago. 2018.

ERPEN, Décio Antonio; PAIVA, João Pedro Lamana; MEZZARI, Mario Pazutti. Condomínio Horizontal de Lotes: Edificação de Livre Escolha do Condômino. In: XVII Encuentro del Comité Latinoamericano de Consulta Registral. 9 al 14 mar. 2003. Morelia/ Michoacan/Mexico. Disponível em: <http://registrodeimoveis1zona.com.br/?p=242>. Acesso em: 27 ago. 2018.

FREITAS, José Carlos de. Da Legalidade dos Loteamentos Fechados. In: Revista dos Tribunais. v. 750. pp. 148 - 170. abr./1998. Doutrinas Essenciais de Direito Registral. v. 4. pp. 1095 - 1124. dez./2011.

GERMANO, Paulo. Moradores instalam cancela em rua da zona sul de Porto alegre e geram polêmica. Gaúcha ZH, 14 jun. 2018. Disponível em:

<https://gauchazh.clicrbs.com.br/colunistas/paulo-germano/noticia/2018/06/moradores-instalamcancela-em-rua-da-zona-sul-de-porto-alegre-e-geram-polemicacjieg15ug0g7z01qoumrft1fw.html>. Acesso em: 22 ago. 2018.

LEMOS, João Rett; MACEDO, Silvio Soares. Condomínios residenciais horizontais fechados na região metropolitana de São Paulo. Paisagem e Ambiente, São Paulo, FAUUSP n.23, 2007, pp. 135-144.

LIMA, Maria Cristina de Brito. Loteamento fechado, associação de moradores. Imposição do rateio associativo a quem não é associado. Revista da EMERJ, Rio de Janeiro, v. 10, n. 40, p. 26-39, out. 2007. 
MELLO, Cláudio Ari. Direito à moradia e conciliação judicial de conflitos coletivos possessórios: a experiência de Porto Alegre. Revista de Direito da Cidade, [S.I.], v. 9, n. 4, p. 2072-2098, out. 2017. ISSN 2317-7721. Disponível em: <http://www.e-

publicacoes.uerj.br/ojs/index.php/rdc/article/view/29663/21990>. Acesso em: 23 ago. 2018.

MELO, Luiz Carlos Figueira de; MELO, Luciana Franco de. Parcelamento do solo urbano: da segurança jurídica à implantação dos loteamentos fechados. Fórum de Direito Urbano e Ambiental: FDUA, Belo Horizonte, v.14, n.83, set./out. 2015.

MUKAI, Toshio. Consolidada a legalidade dos loteamentos fechados. Fórum municipal \& gestão das cidades FMGC, Belo Horizonte, v.4, n.13 (jan./mar. 2016).

Decisão do STF sobre condomínios deitados: basta que tais empreendimentos sejam compatíveis com as diretrizes fixadas no plano diretor. Fórum de direito urbano e ambiental FDUA, Belo Horizonte, v.15, n.85 (jan./fev. 2016).

. O direito de ir e vir e os loteamentos fechados. Revista Magister de Direito Ambiental e Urbanístico - Caderno Imobiliário, Porto Alegre, v.7, n.37, pp. 5-12, ago./set. 2011.

. Vedações às associações de moradores de exigências de pagamento de quem não é associado e a questão nos loteamentos fechados. BDA - Boletim de Direito Administrativo, São Paulo, v.32, n.4 (abr. 2016), pp. 223-225.

. Os loteamentos fechados não podem ser proibidos por lei federal: inconstitucionalidade do Projeto de Lei no 3.057/00. Revista Magister de Direito Imobiliário, Registral, Urbanístico e Ambiental, Porto Alegre, Magister v.1, n.3, dez./jan. 2005/06, pp. 5-10.

OLIVEIRA, Gustavo Burgos de. Loteamento, desmembramento, desdobro, loteamento fechado, condomínio geral, condomínio edilício, condomínio horizontal de lotes e condomínio urbanístico: noções básicas. Disponível em:

<http://www.mprs.mp.br/atuacaomp/not_artigos/id15041.htm.Acesso?impressao=1>. Acesso em: 27 ago. 2018. 
PAIVA, João Pedro Lamana. Condomínio horizontal de lotes. In: 6ạ Reunião Ordinária do Conurb Ministério Público do Estado do Rio Grande do Sul. 9 abr. 2010. Porto Alegre - RS. Disponível em: <www.mprs.mp.br/areas/urbanistico/arquivos/cond_hor.doc>. Acesso em: 27 ago. 2018.

Condomínios horizontais de lotes: a realidade fática nos municípios e sua previsão legal. Disponível em: <http://irib.org.br/be/app/webroot/files/ editor/files/Revista-Jur\%C3\%ADdicalVArtigo-

Lamanapartido.pdf?utm_source=emailmanager\&utm_medium=email\&utm_campaign=Boletim_El etronico_do_IRIB_No_4565_21_de_julho_de_2016>. Acesso em: 27 ago. 2018.

PEREIRA, Ocimar. Moradores pedem permissão de uso de áreas no Morro São Caetano. Prefeitura de Porto Alegre. Relações Institucionais e Articulação Política, 08 abr. 2015. Disponível em: $<$ http://www2.portoalegre.rs.gov.br/smgl/default.php?p_noticia=176874\&MORADORES+PEDEM+P ERMISSAO+DE+USO+DE+AREAS+NO+MORRO+SAO+CAETANO>. Acesso em: 22 ago. 2018.

RIBEIRO, Guilherme Wagner. Competência legislativa na federação brasileira e a disciplina dos "loteamentos fechados". Fórum de Direito Urbano e Ambiental, Belo Horizonte, v. 7, n. 38, pp. 4958, mar./abr. 2008.

RIO GRANDE DO SUL. Lei no 12.192, de 30 de dezembro de 2016. Disponível em: < https://leismunicipais.com.br/a/rs/p/porto-alegre/lei-ordinaria/2016/1220/12192/lei-ordinaria-n12192-2016-cria-no-municipio-de-porto-alegre-o-programa-municipal-de-seguranca-dascomunidades>. Acesso em: 27 ago. 2018.

RIO GRANDE DO SUL. Tribunal de Justiça do Estado do Rio Grande do Sul. Processo no. 903661893.2018.8.21.0001. Autores: Associação Morro São Caetano, Associação dos Proprietários de Imóveis no Morro São Caetano. Réu: Município de Porto Alegre. 2a Vara da Fazenda Pública. Comarca de Porto Alegre.

RIZZARDO, Arnaldo. Condomínio fechado: incidência da Lei no 4.591/64 e limites de área. Revista Jurídica Consulex, Brasília, v. 14, n. 333, p.35-36, 31 nov. 2010.

SILVA, Bruno Mattos e. Legalidade ou ilegalidade dos loteamentos ou condomínios fechados. Fórum de Direito Urbano e Ambiental, Belo Horizonte, v.7, n.42, p.44-47, nov./dez. 2008. 
SILVA, José Afonso da. Direito Urbanístico Brasileiro. 3. ed.São Paulo: Malheiros

SOUZA, Maria Julieta Nunes de. Notas sobre os condomínios fechados na Cidade Alta, Juiz de Fora. Topos, v.1, n.3, jul./dez. 2004, p. 34-43

UEDA, Vanda. Os novos empreendimentos imobiliários e as transformações recentes no espaço urbano de Porto Alegre. Anais: X Encontro de Geógrafos da América Latina. 20 a 26 mar. 2005. Universidade de São Paulo. Disponível em:

<http://observatoriogeograficoamericalatina.org.mx/egal10/Geografiasocioeconomica/Geografiaur bana/52.pdf>. Acesso em: 27 ago. 2018.

Trabalho enviado em 04 de setembro de 2018

Aceito em 17 de janeiro de 2019 